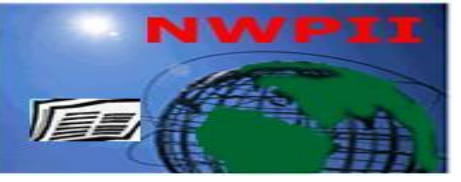

American Journal of Biomedical Sciences

ISSN: 1937-9080

nwpii.com/ajbms

\title{
Association of PI3-kinase and Wnt Signaling in Non-steroidal Anti- Inflammatory Drug-induced Apoptosis in Experimental Colon Cancer
}

\author{
Jasmeet Kaur and S N Sanyal*
}

Department of Biophysics, Panjab University, Chandigarh - 160 014, India

*Corresponding author

Dr S N Sanyal

Professor

Department of Biophysics

Panjab University

Chandigarh - 160014 , India

Phone: +911722534122

Email: sanyalpu@gmail.com

Received: 03 June 2009; | Revised: 18 June 2009; | Accepted: 19 August 2009

\begin{abstract}
In addition to having anti-inflammatory properties, non-steroidal anti-inflammatory drugs (NSAIDs) inhibit neoplastic cell proliferation by inducing apoptosis. Inhibition of cycloxygenase-2 (COX-2) seemed to be the principal target of NSAIDs, as it is overexpressed in several cancers and catalyzes the synthesis of prostaglandin $\mathrm{E}_{2}\left(\mathrm{PGE}_{2}\right)$, the critical proinflammatory molecule. A major role for phosphatidyl inositol 3kinase (PI3-kinase) pathway activation in human tumors has been more recently established. The present study explored the role of PI3-kinase and Wnt molecular pathways in NSAIDs' chemopreventive effect in colon cancer. 1, 2-dimethylhydrazine was used for experimental colon cancer model and diclofenac as the chemopreventive agent. Protein expression of caspase- 3 and 9 and fragmentation of DNA were checked in the colonic tissue. There was a decrease in all the three parameters, indicative of inhibition of apoptosis in the present experimental cancer model. Protein expression of PCNA and proliferation index as determined by both PCNA and BrdU immunostaining were also seen to be increased in the DMH treated animals. DMH upregulated the expression of PI3-kinase, Akt, Wnt and $\beta$-catenin, but reduced the GSK-3 $\beta$ levels. Coadministration with diclofenac, while decreasing PI3-kinase, Akt, Wnt and $\beta$-catenin, also increased the protein level of GSK-3 $\beta$ thus confirming that NSAIDs target PI3-kinase and Wnt signaling to exert the two important actions - induction of apoptosis and inhibition of cellular proliferation.
\end{abstract}

Keywords: NSAID; apoptosis; PI3-kinase; GSK-3ß; Wnt. 


\section{Introduction}

NSAIDs which share the property of inhibiting the cycloxygenase (COX) enzyme, hinder the development of colon and other cancers as well [1]. Although data indicate central role of COX-2 in colon carcinogenesis, however the antineoplastic effects of NSAIDs are partly independent of their ability to inhibit COX-2, such as the modulation of important signaling pathways.

Phosphatidyl inositol 3-kinase (PI3kinase)/Akt pathway is involved in the proliferation of transformed epithelial cell and thus is oncogenic [2, 3]. Also PI3-kinase regulates membrane ruffling, actin rearrangement, vesicular trafficking and cell survival [3]. PI3-kinase catalyzes the phosphorylation of phosphoinositol4 phosphate and phosphoinositol-4, 5 phosphate at the D3 position and activates various downstream elements including Akt/protein kinase B (PKB). Promotion of cell survival by the activation of PI3-kinase/Akt occurs by the inhibition of proapoptotic signals and the induction of survival signals [4-8], which may contribute to malignant transformation. Conversely, the inhibition of PI3kinase/Akt pathway results in cell cycle arrest and differentiation of human colon cancer cell lines, HT29 and Caco-2 [9].

Glycogen synthase kinase-3 $\beta$ (GSK-3 $\beta$ ) is an Akt substrate shown to be inhibited upon phosphorylation by Akt [10]. GSK-3 $\beta$ triggers the degradation and inactivation of several oncogenic transcription factors (e.g c-Jun and c-Myc) and proto-oncoproteins (e.g $\beta$-catenin) by phosphorylating them and thus it is expected to suppress neoplastic transformation and tumor development [11]. GSK-3 $\beta$ is also a negative regulator of $\mathrm{Wnt} / \beta$-catenin pathway and thus is a target of considerable antineoplastic interest [12].

The Wnt/ $\beta$-catenin pathway controls multiple developmental events throughout the animal kingdom and plays a critical role in the development of the gastrointestinal tract [13]. A multiprotein scaffold consisting of adenomatous polyposis coli (APC), glycogen synthase kinase (GSK)-3 $\beta$, axin, and the transcriptional cofactor $\beta$ catenin is central to this pathway. In the absence of Wnt ligands, $\beta$-catenin levels are kept low through constitutive phosphorylation by GSK-3 $\beta$, which leads to the ubiquitination and degradation of $\beta$-catenin [14]. Wnt signaling inhibits GSK-3 $\beta$ activity, reducing phosphorylation and subsequent degradation of $\beta$-catenin. $\beta$-catenin is stabilized and translocates to the nucleus to bind members of the $\mathrm{T}$ cell factor $(\mathrm{Tcf}) / \mathrm{lymphoid-enhancing} \mathrm{factor}$ (LEF) family of transcription factors and induce target gene expression [14-16].

The purpose of the present study is to identify whether diclofenac targets PI3-kinase and/or Wnt signaling pathway for its proapoptotic and antiproliferative effects, which may contribute significantly to the understanding of its chemopreventive efficacy in experimental colon carcinogenesis.

\section{Materials and methods}

Chemicals: $\quad$ 1, 2-dimethylhydrazine dihydrochloride (DMH) and Bradford reagent were purchased from Sigma-Aldrich (St. Louis, MO, USA). Diclofenac was a generous gift from Ranbaxy. Primary antibody against PI3-kinase, Akt, GSK-3 $\beta$, Wnt, $\beta$-catenin, caspase-3, caspase9, BrdU, PCNA and anti-mouse $\beta$-actin were purchased from Santa Cruz Biotechnology Inc., CA (USA). Alkaline phosphatase-conjugated secondary antibodies and BCIP-NBT were purchased from Genei, Bangalore (India). All other chemicals and reagents used in the present study were of analytical grade and procured from the Indian manufacturers.

Animal procurement: Male adult SpragueDawley rats of body weight between 100-120g were obtained from the inbred population of the Central Animal House, Panjab University, Chandigarh. These were acclimatized to the control diet (rodent chow) and water ad libitum for atleast 1 week. Animals were maintained as per the principles and guidelines of the Ethics Committee of Animal Care of Panjab University in accordance with the Indian National Law on animal care and use. The animals were housed three per cage in polypropylene cages with a wire mesh top and a hygienic bed of husk (regularly changed) in a well ventilated animal room till the end of the experimental period. The animals were 
also maintained under a $12 \mathrm{~h}$ photoperiod of light and darkness, respectively.

Treatment schedule: Animals were assorted into the following groups with 4 to 6 animals in each group:

Control Group, Vehicle Treated: Animals were administered the vehicle (1mM EDTA-saline subcutaneously (s.c.) in weekly injection and $0.5 \%$ carboxymethyl cellulose (CMC) per oral (p.o.) daily.

DMH Group: Animals were administered with DMH weekly at a dose of $30 \mathrm{mg} / \mathrm{Kg}$ body weight (s.c.), as had been established in our laboratory earlier (17). DMH was freshly prepared in $1 \mathrm{mM}$ EDTA-saline, $\mathrm{pH}$ adjusted to 7.0 using dilute $\mathrm{NaOH}$ solution.

DMH + Diclofenac Group: Diclofenac was given daily per oral (p.o) at its therapeutic antiinflammatory dose $\left(\mathrm{ED}_{50}\right.$ for rats, $8 \mathrm{mg} / \mathrm{kg}$ body weight) to the animals along with the weekly administration of $\mathrm{DMH}$. The anti-inflammatory dose of diclofenac had been chosen from the work of Winter et al. 1962 (18), following the carrageenan-induced paw oedema model in the rat hind leg.

Diclofenac Group: Diclofenac alone was administered p.o daily ( $8 \mathrm{mg} / \mathrm{kg}$ body weight).

After six weeks, animals were kept on overnight fasting with drinking water ad libitum and sacrificed the next day. The animal body weights in all the groups were recorded once in a week till the termination of the experiment.

Western blot Analysis: Protein samples/nuclear extracts $(100 \mu \mathrm{g})$ from each treatment group were separated on $10 \%$ SDSPAGE. The separated proteins were electrophoretically transferred to nitrocellulose membrane (Genei, Bangalore, India). Immunoblot was prepared using primary antibodies (PI3-kinase - 1:500, Akt - 1:1000, GSK-3 $\beta$ - 1:500, Wnt 1:1000, $\beta$-catenin - 1:1000, Caspase-3 - 1:1000, Caspase-9 - 1:1000, PCNA - 1:1000) from Santa Cruz Biotechnology Inc., CA (USA) and alkaline phosphatase-conjugated respective secondary antibodies at a dilution of 1:10, 000 (Genei, Bangalore, India). BCIP-NBT detection system was used to develop the blot. Bands obtained were densitometrically analyzed using Image $\mathbf{J}$ software and the density expressed as gray values in densitometric units.

For preparation of protein extracts, colons were removed and rinsed from the different treatment groups after completion of 6 weeks. Total lysates were prepared in fresh ice-cold protein lysis buffer $(10 \mathrm{mM}$ Tris, $100 \mathrm{mM} \mathrm{NaCl}$, 5mM EDTA, 1\% Triton-X100, 1mM PMSF and $2 \mathrm{mM}$ DTT $(\mathrm{pH} 8))$. The extracts were cleared by centrifugation at $10,000 \mathrm{rpm}$ for 10 minutes at $4^{\circ} \mathrm{C}$. The supernatants were collected as the total lysate. For nuclear extract, the nuclei were suspended at $0-4^{\circ} \mathrm{C}$ in $50 \mathrm{mM} \mathrm{NaCl}, 10 \mathrm{mM}$ Hepes, pH 7.6, $0.1 \mathrm{mM}$ EDTA, 25\% glycerol and $0.5 \mathrm{mM}$ PMSF and pelleted by centrifugation in an eppendorf centrifuge at 5,000 rpm for $15 \mathrm{~min}$ at $4^{\circ} \mathrm{C}$. Resulting nuclear debris were incubated in the same buffer for $30 \mathrm{~min}$ on ice, centrifuged at $10,000 \mathrm{rpm}$ at $4^{\circ} \mathrm{C}$ for 10 minutes and the resultant supernatant was used as the nuclear extract in the present study. Protein concentration was determined by the method of Bradford [19].

Immunohistochemical localization studies: $5 \mu \mathrm{m}$ thick paraffin sections of rat colon were deparaffinized in two changes of xylene for 10 min each. The sections were then gradually hydrated and brought to water. The non specific staining was blocked by incubating the sections with 2\% BSA in phosphate buffer saline (PBS $10 \mathrm{mM}, \mathrm{pH} 7.2)$. The sections were then incubated with polyclonal antibodies against Akt - 1:1000, GSK-3 $\beta$ - 1:500, Wnt - 1:1000, $\beta$-catenin - 1:1000, PCNA - 1:1000 and BrdU - 1:1000 in a moist chamber for $2 \mathrm{hr}$ at $37^{\circ} \mathrm{C}$. After incubation, the sections were washed in PBS, PBS tween (PBS with $0.05 \%$ tween-20) and PBS successively for $5 \mathrm{~min}$ each. The sections were then incubated with respective alkaline phosphatase-labeled secondary antibodies $(1: 10,000)$ for $2 \mathrm{hr}$. Sections were washed again in the same manner as described above and the reaction product was developed using BCIP-NBT. Reaction was terminated by washing with distilled water after which sections were counterstained with methyl green and mounted in DPX.

Microscopy and Data analysis: Sections were viewed and photographed at 200X with a Leica Optiphot microscope to which was attached a Leica Digital camera. 
DNA Extraction and Analysis of DNA Fragmentation by Gel Electrophoresis: Colonic tissues were homogenized and the pellet suspended in lysis buffer $(50 \mathrm{mM}$ Tris- $\mathrm{HCl}, \mathrm{pH} 8$; $20 \mathrm{mM}$ EDTA, pH 8; 1\% SDS; $0.1 \mathrm{mg} / \mathrm{ml}$ proteinase $\mathrm{K}$ ). The samples were incubated for 2 hrs at $37^{\circ} \mathrm{C}$ with constant shaking. DNA was extracted with 1:1 mixture of phenol:chloroform. After centrifugation for $5 \mathrm{~min}$ at $12,000 \mathrm{~g}$, the aqueous layer was collected and supplemented with one-tenth volume of $6 \mathrm{M}$ sodium acetate, $\mathrm{pH}$ 5.2 and 1 volume of 2-propanol. Samples were stored at $-20^{\circ} \mathrm{C}$ overnight. The precipitated DNA was collected by centrifugation, washed with $70 \%$ ethanol and dissolved in $20 \mu \mathrm{l}$ of Tris-EDTA buffer. The concentration of DNA was estimated by the measurement of optical density at $260 \mathrm{~nm}$. Samples containing $5 \mu \mathrm{g}$ of DNA were then loaded to $1.5 \%$ agarose gels. DNA ladder of $100 \mathrm{bp}$ was used as the standard. Electrophoresis was carried out in TAE buffer (40 mM Tris-acetate, $1 \mathrm{mM}$ EDTA) and DNA was stained with ethidium bromide and photographed with Gel Documentation.

Statistical analysis: Data were expressed as Mean \pm SD of four animals for each group. One way analysis of variance (ANOVA) was done to compare the means between the different treatments using Post-Hoc comparison by Least Significant Difference (LSD) method. The statistical software package SPSS v10 for windows was used for the purpose. A value of $p<$ 0.05 was considered significant in the present study.

\section{Results}

PI3-kinase signaling pathway - To ascertain the plausible role of PI3-kinase and its downstream targets, Akt and GSK-3 $\beta$ in the NSAID-induced apoptosis and inhibition of proliferation, immunohistochemistry as well as Western blot were done (Figure 1 and 2). The results obtained by Western blot demonstrate activation of PI3-kinase and Akt (Figure 1b), and inhibition of GSK-3 $\beta$ (Figure $2 c$ ) in the DMHtreated animals. Co-treatment with diclofenac led to a significant increase in protein expression of GSK-3 $\beta$ and decrease in the expression of PI3- kinase and Akt. The immunohistochemical data of Akt and GSK-3 $\beta$ further supports and strengthens the observation as obtained from Western blot analysis. Akt was found to be expressed primarily in the cytoplasm of colonic epithelial cells (arrows) and also in the stromal cells in the DMH group (Figure 1a). In all the other groups, low expression was seen only in the stromal cells. GSK-3 $\beta$ expression was also found to be cytoplasmic with reduced levels in DMH treated animals and revived levels after diclofenac co-treatment (Figure 2a).

Wnt/B-catenin signaling pathway - As Wnt $/ \beta$-catenin signaling is an important determinant of colonic cellular fate and is found disrupted in adenocarcinoma, we examined its role in the chemoprevention of experimental colon cancer by diclofenac. Treatment of rats with a colon-specific carcinogen, DMH increased the Wnt and $\beta$-catenin levels significantly both in tissue sections and protein/nuclear extracts (Figure $2 \mathrm{a}$ and 2c). However, diclofenac reduced the levels of Wnt and $\beta$-catenin appreciably when administered simultaneously with DMH. Wnt expression in tissue sections was seen to be primarily cytoplasmic however; both cytoplasmic and nuclear expression was seen for $\beta$-catenin. There was a significant increase in the number of $\beta$-catenin positive nuclei after $\mathrm{DMH}$ treatment (Figure 2b). Control as well as diclofenac only groups expressed a low level of Wnt and $\beta$ catenin.

Intestinal proliferation - A characteristic feature of both human colonic cancer and animal colonic cancer model is the high rate of intestinal cell proliferation. In the present study, immunohistochemistry of PCNA and BrdU incorporation in paraffin sections (Figure 3a) and Western blot of PCNA (Figure 3c) were done to probe cellular proliferation. DMH administration resulted in a significant increase in the number of proliferating cell per crypt (Figure $3 \mathrm{~b}$ ). The results were agreeing for both BrdU and PCNA staining. Proliferating indices returned to near control levels after diclofenac co-treatment. Both control as well as diclofenac only groups showed few proliferative cells and that to near the base of the crypts. Further, the intensity of staining was significantly higher in the sections from DMH 
treated rats as compared to all the other groups. The protein level of PCNA in all the groups, as analyzed by Western blot was in agreement with the immunostaining results.
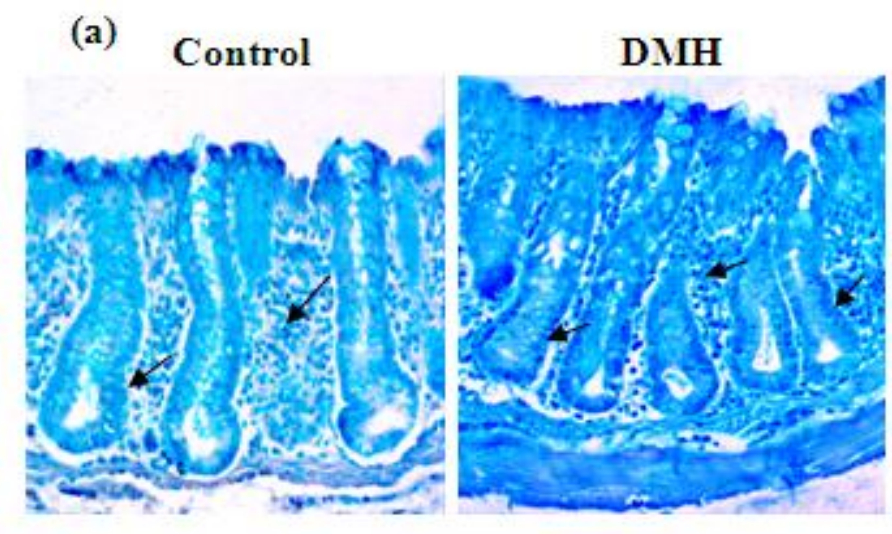

DMH + Diclofenac
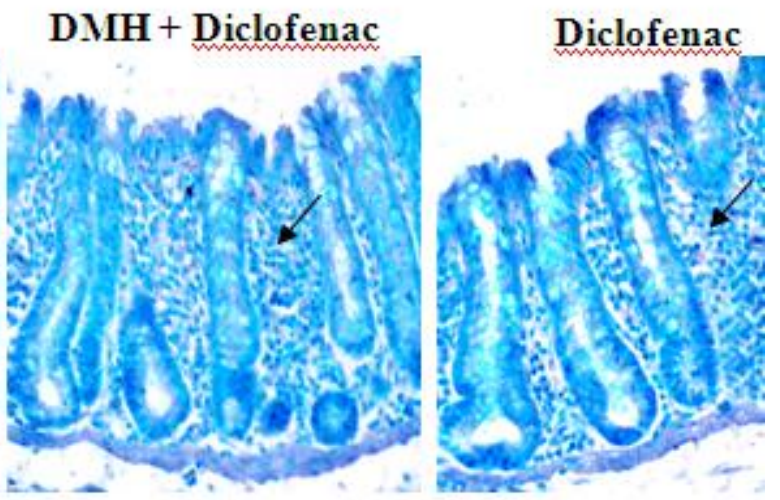

(b)

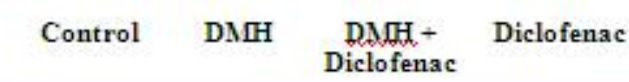

PI3-kinase $(110 \mathrm{kDa})$

Akt $(55 \mathrm{kDa})$
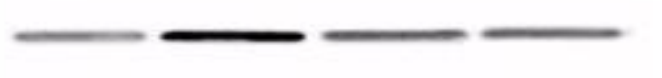

$\longrightarrow$

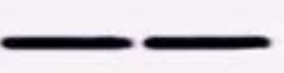

$\beta$-actin $(43 \mathrm{kDa})$

(c)

nControl $=\mathrm{DMH}=\mathrm{DMH}+$ Diclofenac $=$ Diclofenac

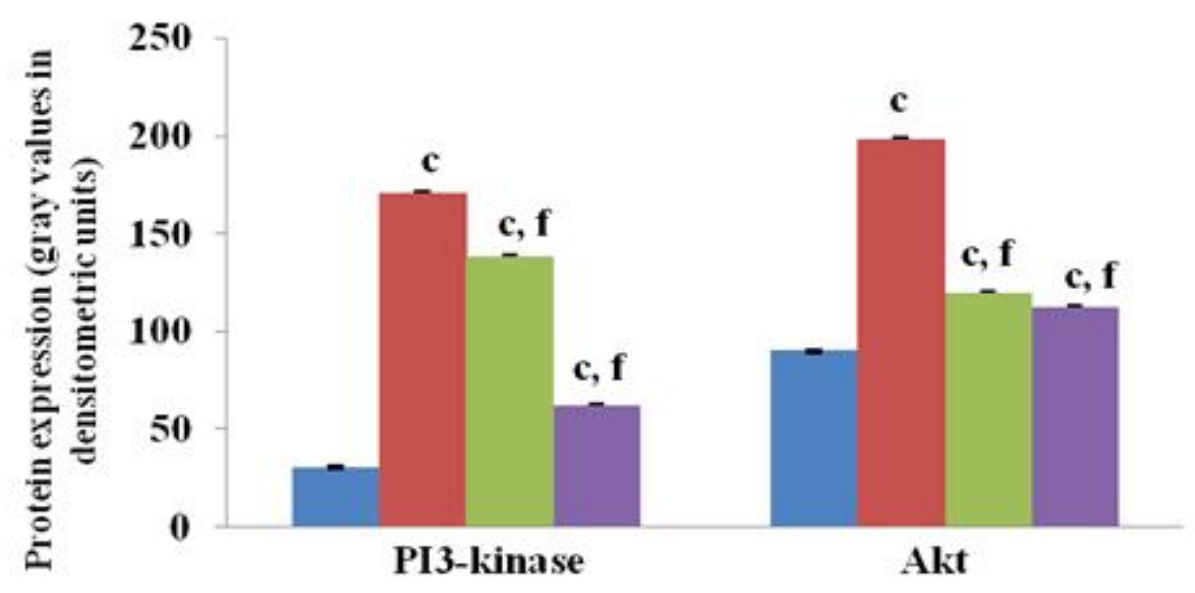

Figure 1: Photomicrographs showing the cytoplasmic expression of Akt (arrows) in paraffin sections and effect of DMH and diclofenac treatment alone and in combination (a). BCIP/NBT gave dark blue color while methyl green stained the sections light green or cyan. Protein expression of PI3-kinase and Akt in protein extracts by Western blot (b) and their densitometric analysis (c). The values are Mean \pm S.D. of 4 animals. ${ }^{c} p<0.001$ in comparison to control and ${ }^{\mathrm{f}} \mathrm{p}<0.001$ in comparison to DMH by one way ANOVA. 
(a)

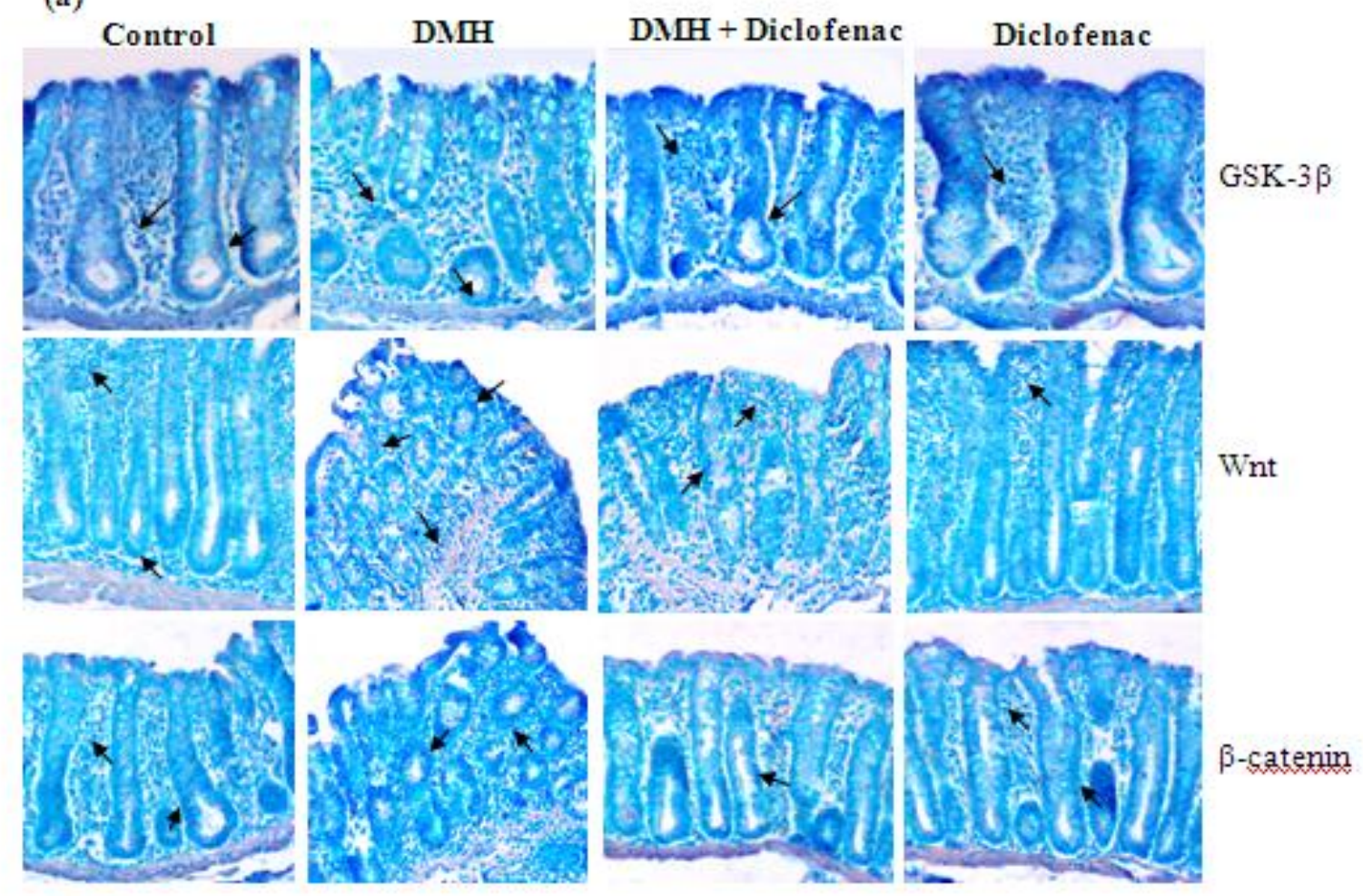

(b)
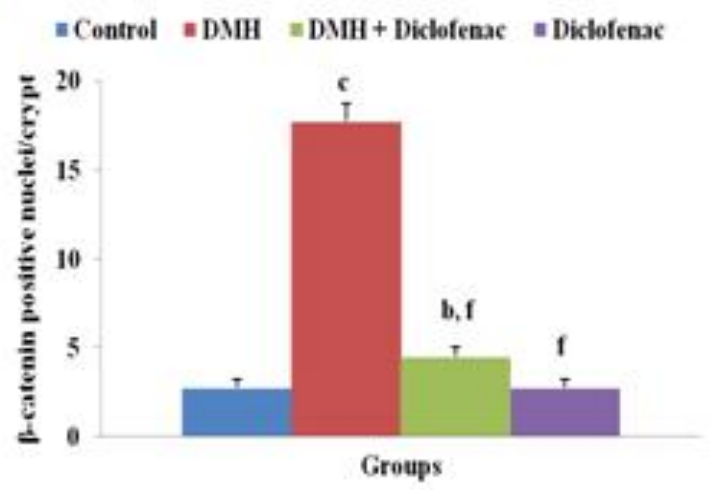

(c)

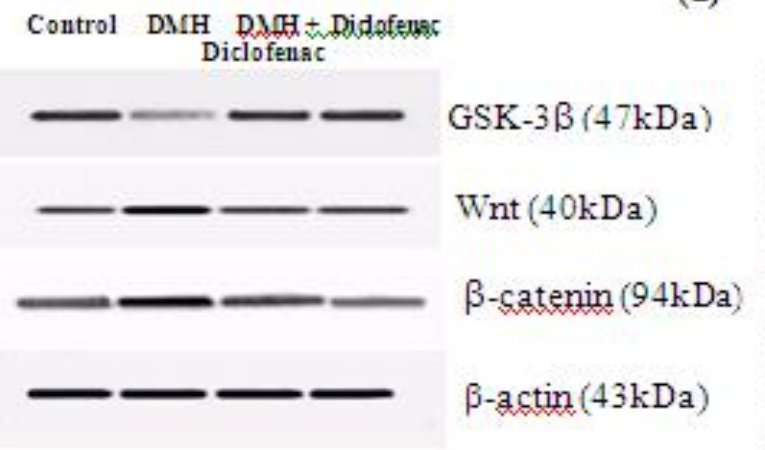

(d)

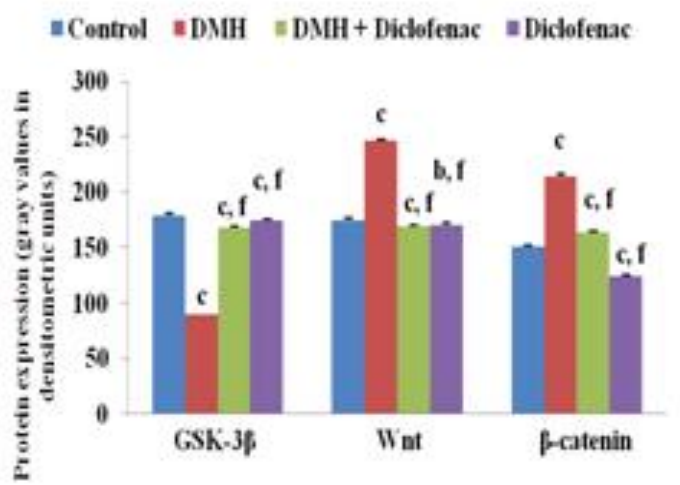

Figure 2: Photomicrographs showing the cytoplasmic expression of GSK-3 $\beta$ and Wnt (arrows) and both cytoplasmic as well as nuclear expression of $\beta$-catenin in each group (a). 2(b) shows the counting of $\beta$-catenin positive nuclei/crypt. Effect of DMH and diclofenac treatment alone and in combination on the protein levels of GSK-3 $\beta$, Wnt and $\beta$-catenin by Western blot (c) and their densitometric analysis (d). The values are Mean \pm S.D. of 4 animals. ${ }_{\mathrm{p}}^{\mathrm{p}}<0.01,{ }^{\mathrm{c}} \mathrm{p}<0.001$ in comparison to control and ${ }^{\mathrm{f}} \mathrm{p}<0.001$ in comparison to DMH by one way ANOVA. 


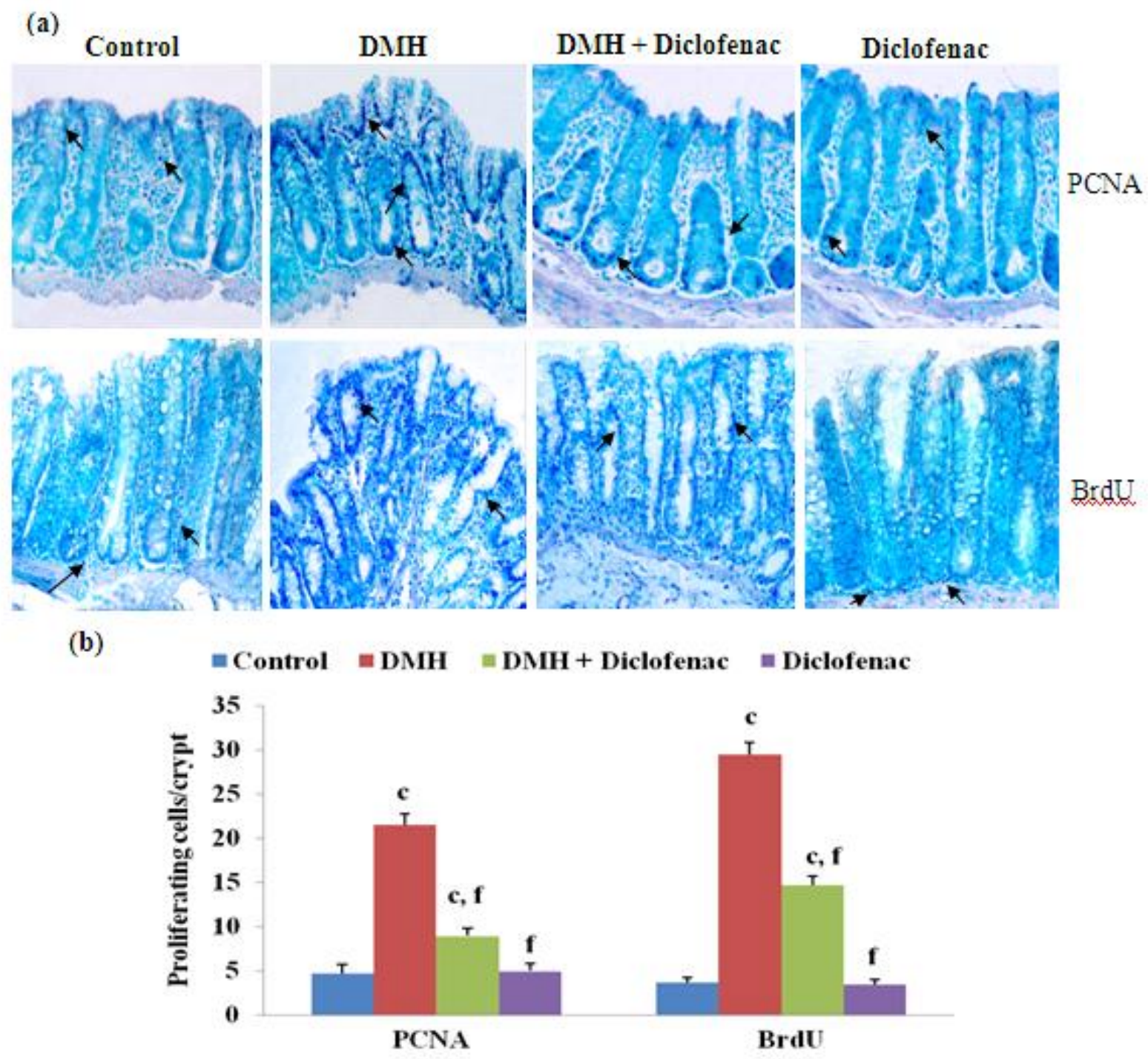

(d) $\quad$ Control $\equiv \mathrm{DMH}=\mathrm{DMIH}+$ Diclofemac $=$ Diclofenac

(c)

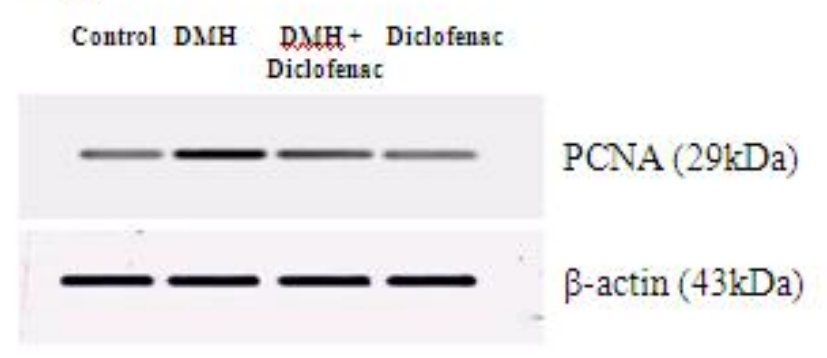

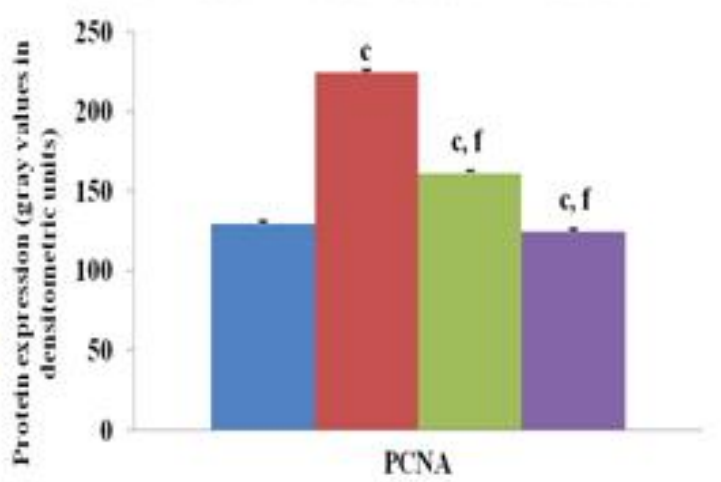

Figure 3: Effect of DMH and diclofenac treatment alone and in combination on the expression of PCNA and BrdU in paraffin sections (a) and proliferation index (proliferating cells/crypt) is shown in (b). Protein expression of PCNA in nuclear extract by Western blot (c) and its densitometric analysis (d) from each group. The values are Mean \pm S.D. of 4 animals. ${ }^{\mathrm{c}} \mathrm{p}<0.001$ in comparison to control and ${ }^{\mathrm{f}} \mathrm{p}<0.001$ in comparison to DMH by one way ANOVA. 
(a)
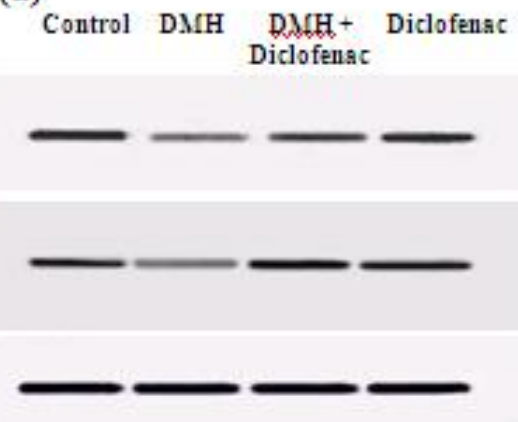

(b)

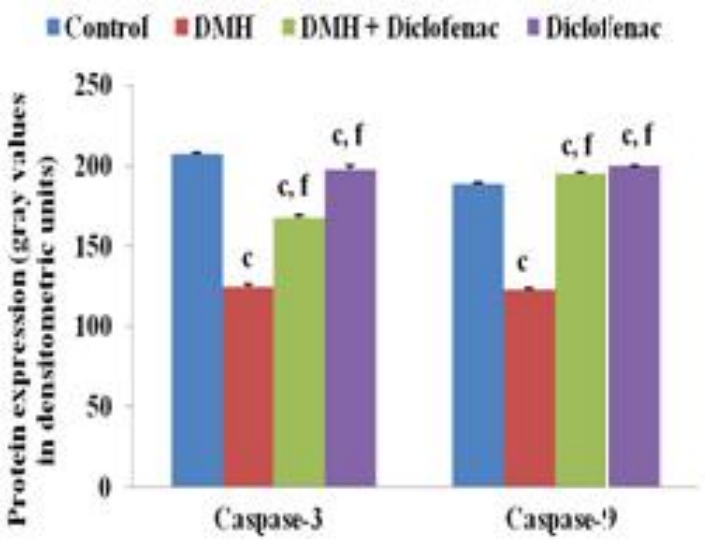

(c)

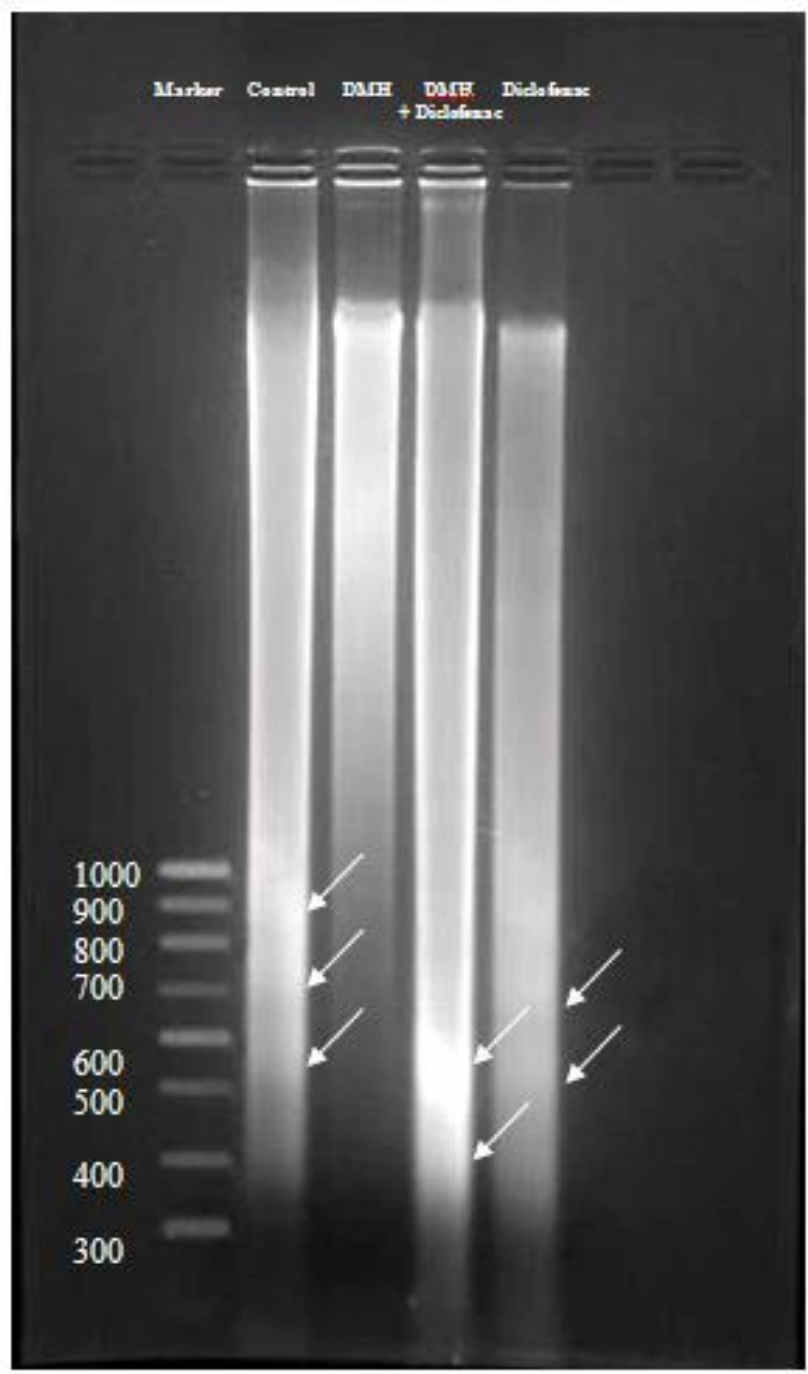

Figure 4: Effect of DMH and diclofenac treatment alone and in combination on the protein expression of Caspase-3 and 9 by Western blot (a) and its densitometric analysis (b). Fragmentation of DNA from each group is shown in (c). The values are Mean \pm S.D. of 4 animals. ${ }^{c} \mathrm{p}<0.001$ in comparison to control and ${ }^{\mathrm{f}} \mathrm{p}<0.001$ in comparison to $\mathrm{DMH}$ by one way ANOVA. 
Proteins involved in regulation of apoptosis - Deregulation of apoptosis is a central event in many malignancies including cancer and evidence supports the role of NSAIDs in tumor chemoprevention by induction of apoptosis. In the present study, we studied the expression of caspase- 3 and caspase-9 (Figure 4a) by Western blot to evidence NSAID-induced apoptosis. The expressions were found to decrease significantly after DMH treatment in rat colon as compared to control and diclofenac only groups. As caspase-9 is involved in the activation of the caspase cascade responsible for apoptosis execution and in turn, cleaves and activates the effector caspases, its decreased expression may be responsible for reduced protein expression of caspase-3. The colons from $\mathrm{DMH}+$ diclofenac treated group showed the restored levels of both the caspases.

DNA fragmentation - Breakdown of nuclear DNA into its nucleosomal fragments is a key feature of the programmed cell death or apoptosis. Fragments of DNA from colonic tissue were extracted by phenol:chloroform method and analyzed on agarose gel electrophoresis from each group. DMH treated animals showed the intact genomic DNA near the well with no fragments whereas all other groups showed prominent fragmentation (Figure 4c).

\section{Discussion}

The present study was designed to gain insight into the molecular mechanism and potential targets of NSAIDs' proapoptotic and anti-proliferative effects against colon cancer. PI3kinase/Akt is a major signaling pathway which is oncogenic and mediates proliferative signals in intestinal epithelial cells in vitro and in vivo [20]. Thus blocking this pathway by a chemical, pharmacological or molecular method can inhibit proliferation and restore the accepted levels of apoptosis. Our results showed modulation of PI3kinase/Akt pathway after DMH treatment, which may be responsible for the observed anti-apoptotic and proliferative effects of DMH. The elevated levels of Akt as a result of PI3-kinase activation seem responsible for the reduced levels of GSK$3 \beta$ in the present study. The immunohistochemistry of Akt in paraffin sections from DMH group supported a high expression of Akt in both epithelial and stromal cells, whereas only a few stromal cells were seen expressing Akt in all other groups. GSK-3 $\beta$ was reduced significantly by $\mathrm{DMH}$ treatment, however diclofenac improved the levels. Results from immunohistochemistry of GSK-3 $\beta$ coincided well with the results from protein expression study by Western blot.

Deregulation of $\mathrm{Wnt} / \beta$-catenin pathway plays a key role in the development of colorectal cancer [15]. Increased levels of constitutively active $\beta$ catenin/Tcf-4 complex are observed in the nuclei of colon cancer cells [21]. In the Wnt signaling cascade, APC, axin and GSK-3 $\beta$ constitute the destruction complex which controls the stability of $\beta$-catenin. In the absence of Wnt signals, GSK-3 $\beta$ phosphorylates $\beta$-catenin, thus marking it for proteasomal degradation. Wnt signaling inhibits GSK-3 $\beta$ activity, as a result $\beta$-catenin would no longer be phosphorylated and accumulate to form nuclear complexes with TCF/LEF factors. The rat colons after DMH treatment showed significantly increased levels of both Wnt and $\beta$-catenin in the present study. However, diclofenac co-treatment led to appreciable decrease in the expression of both the proteins. It may be suggested that diclofenac elevated the levels of GSK-3 $\beta$ by inhibiting PI3-kinase and the former thus phosphorylates $\beta$-catenin to degradation. Further level of Wnt itself was reduced by diclofenac coadministration, thus Wnt too could not inhibit the GSK-3 $\beta$ and subsequent phosphorylation of $\beta$ catenin.

Apoptosis involves the activation of caspases, which occurs in two steps: a so-called "initiator" caspase (either caspase- 8 or caspase-9) is activated upon adapter-mediated oligomerization, and the active initiator caspase then activates the "effector" caspase, caspase-3 (and other effector caspases) by limited proteolysis [22]. Caspases are directly regulated by phosphorylation and Akt phosphorylates caspase-9, thus inhibiting it [23]. Apoptosis was investigated by caspase- 3 and caspase-9 protein expression and DNA fragmentation. The protein levels of both caspase3 and 9 were seen to reduce significantly after $\mathrm{DMH}$ treatment, showing inhibition of the 
classical apoptotic pathway. DNA fragmentation analysis also did not evidence low molecular weight fragments in the DMH group, which is a typical feature of apoptosis. Increased levels of both the caspases and fragmentation of DNA after diclofenac co-treatment reveal proapoptotic efficacy of NSAID in colon cancer. It is possible that diclofenac is functioning through uninhibited GSK-3 $\beta$ to re-establish the homeostatic levels of apoptosis.

BrdU is a thymidine analogue which, after incorporation into normal and malignant cells during the S-phase of the cell cycle, can be detected using a monoclonal antibody and its immunohistochemistry offers several advantages over thymidine autoradiography [24]. BrdU in situ cell labeling was employed to determine crypt cell proliferation in rat colons after DMH and DMH + diclofenac treatment. Hyper-proliferative crypts were observed in the tissue sections from the DMH group. The proliferative index (proliferating cells/crypt) was normalized notably after diclofenac co-treatment, establishing the NSAIDs' anti-proliferative upshot. As proliferation is a key event in the development and normal functioning of intestine, BrdU positive cells were seen at the base of the crypts in the control and diclofenac only groups.

Expression of proliferating cell nuclear antigen (PCNA) by cells during the $\mathrm{S}$ and G2 phases of the cell cycle makes the protein a good cell proliferation marker [25]. It also actively participates in a number of the molecular pathways responsible for the life and death of the mammalian cell [26]. The proliferative index (proliferating cells/crypt) was significantly increased in the DMH treated rats compared with the control and diclofenac only group. Diclofenac was able to reduce the index considerably when given along with the DMH.

Our study suggests that PI3-kinase/Akt and Wnt/ $\beta$-catenin pathway mediates key signals for intestinal epithelial proliferation and inhibition of apoptosis in an experimental model of colon cancer. Inhibition of both of these pathways and induction of GSK-3 $\beta$ as a common downstream target after diclofenac co-administration can be suggested as the potential molecular mechanism for diclofenac ability to induce apoptosis in colonic proliferating cells. This might possibly contribute to better understanding of the chemopreventive effect of NSAIDs and development of targeted drugs for colon cancer with more effectiveness and safety.

\section{Acknowledgement}

Financial assistance from the Council of Scientific and Industrial Research (CSIR), Govt. of India (37(1308)/07/EMR-II) is gratefully acknowledged.

\section{References}

1. Ricchi, P.; Zarrilli, R.; Palma, A. D.; Acquaviva, A. M. Nonsteroidal antiinflammatory drugs in colorectal cancer: from prevention to therapy, $B r J$ Cancer, 2003, 88,803-807.

2. Sheng, H.; Shao, H.; DuBois, R. N. Akt/PKB activity is required for Ha-Ras mediated transformation of intestinal epithelial cells, $J$ Biol Chem, 2001, 276,14498-14504.

3. Laprise, P.; Chailler, P.; Houde, M.; Beaulieu, J. F.; Boucher, M. J.; Rivard, N. Phosphatidylinositol 3-kinase controls human intestinal epithelial cell differentiation by promoting adherens junction assembly and p38 MAPK activation, J Biol Chem, 2002, 277,8226-8234.

4. Roche, S.; Koegl, M.; Courtneidge, S. A. The phosphatidylinositol 3-kinase alpha is required for DNA synthesis induced by some, but not all, growth factors, Proc Natl Acad Sci, USA, 1994, 91,9185-9189.

5. Philpott, K. L.; McCarthy, M. J.; Klippel, A.; Rubin, L. L. Activated phosphatidylinositol 3-kinase and Akt kinase promote survival of superior cervical neurons, J Cell Biol, 1997, 139, 809-815.

6. Davidson, H. W. Wortmannin causes mistargeting of procathepsin D, evidence for the involvement of a phosphatidylinositol 3kinase in vesicular transport to lysosomes, $J$ Cell Biol, 1995, 130, 797-805.

7. Jones, S. M.; Howell, K. E. Phosphatidylinositol 3-kinase is required for the formation of constitutive transport

(C) 2009 by NWPII. All rights reserved. 
vesicles from the TGN, J Cell Biol, 1997, 139,339-349.

8. Vanhaesebroeck, B.; Leevers, S. J.; Ahmadi, K.; Timms, J.; Katso, R.; Driscoll, P. C.; Woscholski, R.; Parker, P. J.; Waterfield, M. D. Synthesis and function of 3phosphorylated inositol lipids, Annu Rev Biochem, 2001, 70,535-602.

9. Wang, Q.; Wang, X.; Hernandez, A.; Kim, S.; Evers, B. M. Inhibition of the phosphatidylinositol 3-kinase pathway contributes to HT29 and Caco-2 intestinal cell differentiation, Gastroenterology, 2001, 120,1381-1392.

10. Zheng, W. H.; Kar, S.; Quirion, R. Insulin-like growth factor-1-induced phosphorylation of the Forkhead Family Transcription Factor FKHRL1 is mediated by Akt kinase in PC12 cells, J Biol Chem, 2000, 275,39152-39158.

11. Manoukian, A. S.; Woodgett, J. R. Role of glycogen synthase kinase 3 in cancer: regulation by Wnts and other signaling pathways, Adv Cancer Res, 2002, 84,203229.

12. Shakoori, A.; Ougolkov, A.; Yu, Z. W.; Zhang, B.; Modarressi, M. H.; Billadeau, D. D.; Mai, M.; Takahashi, Y.; Minamoto, T. Deregulated GSK3beta activity in colorectal cancer: its association with tumor cell survival and proliferation, Biochem Biophys Res Commun, 2005, 334(4), 1365-1373.

13. Jansson, E. A.; Are, A.; Greicius, G.; Kuo, I. C.; Kelly, D.; Arulampalam, V.; Pettersson, S. The Wnt/ $\beta$-catenin signaling pathway targets PPAR $\gamma$ activity in colon cancer cells, Proc Natl Acad Sci, USA, 2005, 102(5),1460-1465.

14. Theodosiou, N. A.; Tabin, C. J. Wnt signaling during development of the gastrointestinal tract, Dev Biol, 2003, 259(2),258-271.

15. Giles, R. H.; Es, J. H. V.; Clevers, H. Caught up in a Wnt storm: Wnt signaling in cancer, Biochim Biophys Acta, 2003, 1653(1),1-24.

16. Barker, N.; Morin, P. J.; Clevers, H. The YinYang of TCF/beta-catenin signaling, $A d v$ Cancer Res, 2000, 77,1-24.

17. Kanwar, S. S.; Vaiphei, K.; Nehru, B.; Sanyal, S. N. Antioxidative effects of non-steroidal anti-inflammatory drugs during the initiation stages of experimental colon carcinogenesis in rats, J Environ Pathol Toxicol Oncol, 2008, 27(2),89-100.

18. Winter, C. A.; Risley, E. A.; Nuss, G. W. Carrageenan induced oedema in hind paw of the rat as an assay of anti-inflammatory drugs, Proc Soc Exp Biol Med, 1962, 111,544-547.

19. Bradford, M. M. A rapid and sensitive method for the quantitation of microgram quantities of protein utilizing the principle of proteindye binding, Anal Biochem, 1976, 72,248254.

20. Sheng, H.; Shao, J.; Townsend, C. M. Jr.; Evers, B. M. Phosphatidylinositol 3-kinase mediates proliferative signals in intestinal epithelial cells, Gut, 2003, 52,1472-1478.

21. Korinek, V.; Barker, N.; Morin, P. J.; Wichen, D. V.; Weger, R. D.; Kinzler, K. W.; Vogelstein, B.; Clevers, H. Constitutive Transcriptional Activation by a $\beta$-Catenin-Tcf Complex in $\mathrm{APC}^{-1-}$ Colon Carcinoma, Science, 1997, 275,1784-1787.

22. Earnshaw, W. C.; Martins, L. M.; Kaufmann, S. H. Mammalian caspases: structure, activation, substrates, and functions during apoptosis, Annu Rev Biochem, 1999, 68:383424.

23. Cardone, M. H.; Roy, N.; Stennicke, H. R.; Salvesen, G. S.; Franke, T. F.; Stanbridge, E.; Frisch, S.; Reed, J. C. Regulation of cell death protease caspase- 9 by phosphorylation, Science, 1998, 282,1318-1321.

24. Ma, Q.Y.; Williamson, K. E.; Rowlands, B. J. Variability of cell proliferation in the proximal and distal colon of normal rats and rats with dimethylhydrazine induced carcinogenesis, World J Gastroenterol, 2002, 8(5),847-852.

25. Johnson, D. G.; Walker, C. L. Cyclins and cell cycle checkpoints, Annu Rev Pharmacol Toxicol, 1999, 39,295-312.

26. Paunesku, T.; Mittal, S.; Protic, M.; Oryhon, J.; Korolev, S. V.; Joachimiak, A.; Woloschak, G. E. Proliferating cell nuclear antigen (PCNA): ringmaster of the genome, Int J Radiat Biol, 2001, 77,1007-1021. 